\title{
AUSTEN, BRONTE, ELIOT (SOBRE ÉTICAS Y PERSONAJES)
}

\author{
por Hernán Lara Zavala
}

La crítica marxista ha señalado que toda obra de arte refleja inevitablemente la base ideológica sobre la que se apoya el artista; que toda idea deviene a la postre en ideología y que la técnica narrativa -para no mencionar la anécdota- conlleva inevitables implicaciones de orden moral y social. El corolario de esta suposición es que toda novela refleja, simultáneamente a la anécdota que relata, una posición ética por más que el novelista -consciente o inconscientemente- se haya propuesto la crítica o abolición de "otras normas morales".

Lukács comentaba pertinentemente que así como el carácter de los individuos se manifiesta en último análisis a través de sus acciones, así también el carácter ideológico o moral de una obra se revela a través de las alternativas formales y dramáticas que elige un autor en detrimento de otras. ${ }^{1}$ Estas observaciones en torno a la perspectiva formal y temática desde la que un novelista se impone narrar una historia pueden resultar sumamente útiles y esclarecedoras si se evita subordinar todas las variantes ideológicas a una única, ejemplar e inamovible visión del mundo, cualquiera que ésta sea.

Con el planteamiento anterior en mente se ha intentado comparar a tres escritoras inglesas: Jane Austen, Emily Brontë y George Eliot, en relación a tres de sus obras que acusan una cierta similitud anecdótica y de intención: Pride and Prejudice (1813), Wuthering Heights (1847) y Middlemarch (1871), con objeto de iluminar la respectiva visión del mundo que subyace en cada una de las novelas. Se tratará, en la medida de lo posible, de señalar las diversas inclinaciones morales que refleja cada autora y que se manifiestan temática y formalmente en sus respectivas obras. Debe aclararse que no se pretende relacionar los aspectos exteriores de las escritoras -ni en sus biografías, psicologías o sociologías- con sus novelas, a pesar de los muchos puntos en común que comparten las tres (de lengua, de nacionalidad, de momento histórico, de interés en la novela, de vivir en provincia; dos de ellas ser hijas de ministros anglicanos y de haber muerto célibes y la tercera de haber preservado su soltería hasta una edad poco

1 Georg Lukács, Marxism and Human Liberation: "As individual character manifests itself in life's moments of decision, so too in literature”, p. 285. 
común para la época); se trata, en cambio, de comparar las diferentes actitudes que cada una de ellas adopta en torno a problemas específicos y comunes a las tres novelas elegidas.

En efecto, las tres obras tratan, en términos generales, una inquietud similar: el papel social y sentimental que el amor y el matrimonio jugaban en la provincia inglesa durante el siglo diecinueve. En las tres novelas existe una hero'́na que funciona a manera de alter ego de la autora a través de Ia cual refleja su visión del mundo; en el caso de las obras estudiadas estas heroínas son Elizabeth Bennet, Catherine Earnshaw y Dorothea Brooke, respectivamente. Por otra parte, en las tres obras hay un personaje -del que se enamorará finalmente la heroína- que se describe como el prototipo ideal de la masculinidad y quien ha de complementar la personalidad de la protagonista principal. Estas novelas comparten también el principio de que la riqueza, la propiedad y la posición social desempeñan un importante papel dentro de la estrategia adoptada para llegar al matrimonio. La famosa primera frase de Pride and Prejudice que reza: "Es una verdad universalmente aceptada que un soltero en posesión de una cuantiosa fortuna debe hallarse en busca de una esposa"2 se convierte, al final del libro, en su inversa, como Dorothy Van Ghent ${ }^{3}$ lo ha señalado con aguda suspicacia:

una soltera debe hallarse en busca de un hombre de cuantiosa fortuna. En esta superposición del sentido inverso sobre el sentido literal de la frase, se resume el aparentemente modesto argumento que pone a accionar las principales fuerzas en conflicto del libro: una decorosa convención del amor (que sostiene que el hombre lleva la iniciativa) abraza a una exigencia económica (la compulsión de la mujer insolvente por buscar la "propiedad" masculina), y en el abrazo verbal aparecen como una unidad.

En esta novela Elizabeth Bennet - la protagonista- está caracterizada por Jane Austen como una mujer inteligente, graciosa y sobre todo sensata y con sentido común. No se trata de una mujer bella ya que Darcy -el protagonista- la califica de "tolerable" cuando la ve por primera vez; pero la autora maneja a su heroína de tal manera que, a medida que avanza la la novela, sus cualidades intelectuales y morales se elevan por encima de su carente belleza física. Elizabeth se transforma así poco a poco ante los azorados ojos de Darcy hasta que se enamora de ella. Jane Austen elige cuidadosamente los rasgos importantes para caracterizar a su heroína y con ello establece los juicios de valor sobre los que descansa su visión del mundo. Uno de los recursos interesantes de notar en las novelas de Austen es que cada uno de los caracteres femeninos busca como pareja a un hombre cuyo

2 Pride and Prejudice. (La traducción es del autor del ensayo), p. 51.

3 Van Ghent, D., The English Novel. (Traducción del autor), p. 105. 
carácter moral resulte equivalente al suyo aun cuando difieran en nivel social. De ahí que la relación entre las hermanas sea de tanta importancia, ya que el cortejo y el matrimonio se contemplan como un serio e intrincado juego en el que cada participante debe correr sus riesgos para buscar y encontrar a su pareja que en última instancia será su equivalente moral. Jane, por ejemplo, la hermana apacible y simplona de la familia, se casa con Bingley, a quien Elizabeth considera como "un personaje bastante predecible". Bingley se caracteriza en la novela por ser un hombre de buenos sentimientos, aunque siempre dominado por la presencia de su amigo Darcy, de modo similar a como Jane y el resto de las hermanas son manipuladas por Elizabeth. Bingley y Jane representan el paradigma de la pareja sencilla y despreocupada que toma la vida como viene y a la que corresponde inevitablemente un final feliz. En contraste, tanto Collins como Wickham se sienten naturalmente inclinados a cortejar a Elizabeth. Ambos fracasan ya que la heroína se halla en un nivel moral superior al de ellos de acuerdo con el orden jerárquico impuesto por la propia novelista, lo que los lleva a buscar a su pareja entre las otras mujeres de menor rango. Charlotte Lucas, a la que Jane Austen caracteriza como la más deleznable entre las mujeres de la novela (no es ni inteligente ni bonita, polos extremos entre los que oscila el rango de valoración austeniana), es a la que finalmente le corresponde aceptar la propuesta de matrimonio proveniente del gárrulo, pretencioso y ridículo Collins, ya que ella también está consciente de sus propias limitaciones. Lydia, que aunque ostenta belleza física es la menos inteligente de entre las hermanas Bennet, se casa con Wickham, el soldado aventurero e inmaduro que, aunque bien parecido, está personificado como un ser bajo y deshonesto. Es significativo notar que, con la dosis de sarcasmo que caracteriza a la autora, Wickham es el yerno favorito de Mrs. Bennet, con lo cual Jane Austen recalca con humor el poco criterio de la madre de las Bennet, defecto que el lector percibe a través de toda la novela y que tiene ya antecedentes en el apoyo que la señora le brindara a Collins en su intento de casarse con Elizabeth. A través de Lydia, Austen presenta su opinión acerca de lo que es un matrimonio poco afortunado. A través de Charlotte critica el matrimonio conformista realizado con fines puramente bastardos.

Así que aun en el mundo de intereses materiales de Jane Austen, en donde el matrimonio se contempla como un juego de intercambios económicos y sociales, los impulsos de los personajes están subordinados en última instancia a ciertos escrúpulos de índole moral.

Elizabeth y Darcy son los que, sin lugar a dudas, constituyen los protagonistas más complejos de la novela. Es a través de ellos que la autora ilustra al lector sobre su noción de lo que es "a good solid marriage". Ellos ocupan, en efecto, la cima de la pirámide erguida por Austen para valorar sus anhelos éticos y sociales. Como personajes son totalmente previsibles 
en sus actos y de antemano el lector adivina que terminarán casándose. Pero en este tipo de novela el suspenso no depende tanto del desenlace como de los obstáculos que héroe y heroína deben librar para alcanzar su preciado fin: casarse. El principal defecto de Darcy es el de ser sumamente altivo y petulante; el defecto de Elizabeth es el de estar prejuiciada contra los terratenientes adinerados como el propio Darcy. De allí el título de la novela. Antes de que Elizabeth y Darcy logren entenderse, ambos deben superar sus defectos que, más que de orden moral, son de urbanidad. Austen nunca plantea la diferencia social entre los Darcy o los Bingley (terratenientes adinerados) y los Bennet (clase media de provincia) como un impedimento para su matrimonio. Son las diferencias de actitud lo que les impide entenderse de principio. Pero en el mundo de Jane Austen la urbanidad es parte de la moral y para la autora no existe moral sin urbanidad. No es sino hasta que Elizabeth logra que Darcy ceda en su orgullo y en su vanidad que ella decide vencer sus prejuicios en contra de él y los de su clase. Entonces pueden casarse y al hacerlo ser felices. Pero no debe sacarse a Jane Austen de su contexto histórico. Ella no hacía sino reflejar su momento histórico. Durante esta primera fase de la novela victoriana la mujer se consideraba -aunque en un sentido radicalmente distinto al del hombre- como parte de una propiedad. Pasaba de la propiedad paterna a la del marido. El matrimonio representaba para ella un evento final y definitivo. Una vez casada, una mujer no tenía posibilidad de ulteriores desarrollos y menos aún de nuevas relaciones emocionales salvo las que le proporcionaban sus propios hijos. Por lo mismo era común que los novelistas cerraran sus obras con un matrimonio. A medida que transcurre el tiempo, empero, los novelistas se percatan de que el matrimonio no es un fin sino más bien un principio. Es curioso notar que acaso la menos perspicaz, pero también la más franca, de entre los personajes de Pride and Prejudice, Mrs. Bennet, es la que nos ofrece, como lectores, una clara idea de la ganancia que significaba para la época que Elizabeth se casase finalmente con Darcy:

¡Dios mío! ¡Dios nos bendiga! ¡Sólo de pensar en Mr. Darcy! ¿Qué bien! ¿Quién lo hubiera creído! ¡Y es verdad! ¡Ah, querida Lizzy! ¿Qué rica y qué importante serás! ¿Qué de dinero, qué joyas, qué carruajes tendrás! Jane no es nada comparada contigo, nada. Estoy tan contenta, tan feliz. ¿Un hombre tan encantador! 'Tan guapo! ITan alto! IAh querida Lizzy! Pídele que me disculpe porque no me caía bien. Espero que no le importará. ¡Querida, querida Lizzy! ¡Una casa en la ciudad! ¡Todo lo que te plazca! ¡Tres hijas casadas! ¡Diez mil libras al año! ¡Dios mío! ¡Qué será de míl ,Voy a volverme loca! (p. 386).

En la narrativa de Jane Austen el matrimonio se contempla como un problema de correspondencia y concordia entre urbanidad y costumbres por 
un lado, e intereses económicos, por otro. En el lenguaje que ella usa, como Shorer y Van Ghent han señalado, 4 los intereses económicos están estrechamente relacionados con los sentimentales y por lo tanto abundan palabras como "fortuna", "propiedad", "posesión", "establishment", etc. Pero la vena narrativa de Austen corresponde invariablemente a la de la comedia, aun cuando trate incidentalmente algunos temas con cierta seriedad y en un estilo irónico y refinado. Acaso por ello nunca tocó cierto tipo de conflictos más complejos o dolorosos como pueden ser los de la soltería, el adulterio, el divorcio o la insatisfacción conyugal. Hasta Charlotte Lucas y Lydia Bennet, a pesar de los errores en los que incurren y que Jane Austen señala con aguda ironía, logran casarse al final de la novela de una manera absolutamente convencional.

Publicada unas cuantas décadas después de Pride and Prejudice, Wuthering Heights establece un marcado contraste ya que desafía de una manera radical las convenciones y la moral de su tiempo. El marco de la novela tiene mucho en común con la novela de Austen, pues en ella también se exploran la correspondencia entre riqueza y propiedad, por una parte, y las relaciones maritales, por la otra, así como la tensión entre atracción emocional entre los personajes y las conveniencias económicas. Catherine Earnshaw comete un error al elegir a su esposo. Como en el caso de Elizabeth Bennet, Catherine cree que prefiere a Edgar Linton a causa de su riqueza, de su apariencia física y de su posición social; así se lo confiesa abiertamente a Nelly Dean en un desplante de sinceridad, aunque no por ello deje de reconocer que su futuro esposo tiene poco o nada que ver con lo que ella juzga como su más auténtico ser. Con Heathcliff, en cambio, siente una total identificación y si lo rechaza es porque, según le comenta a Nelly, casarse con él la degradaría y los convertiría a ambos en limosneros:

Ahora sería mengua para mí casarme con Heathcliff; nunca sabrá cómo le amo; y no porque sea guapo, Nelly, sino porque él es más yo que yo misma. Cualquiera que sea la sustancia de que estén hechas nuestras almas, la suya y la mía son iguales, y la Linton es tan diferente como el rayo de luna del relámpago, o como el hielo del fuego... ¿no se te ha ocurrido nunca pensar que si Heathcliff y yo nos casáramos, seríamos unos pordioseros? (pp. 158-160).

Mark Shorer ha señalado que con el fin "de exaltar el poder de los sentimientos humanos", Emily Brontë construye sus analogías a través de "la ferocidad de los animales y de la vida implacable de elementos como el fuego, el aire y el agua". 5 En efecto, en la cita anterior podemos notar que Linton está caracterizado a través de las imágenes del claro de luna y la escarcha $-\mathrm{y}$ Heathcliff, por el relámpago y el fuego. Muy pocas novelas postulan de

4 Mark Shorer, The World We Imagine, pp. 4-10.

5 Shorer, op. cit., p. 30. 
manera tan clara la dicotomía que existe entre los intereses económicos y los impulsos pasionales, entre la represión racional y la fuerza vital. Emily Brontë plantea con toda claridad la disyuntiva a la cual debe enfrentarse su protagonista:

Mi amor a Linton es como el follaje de los bosques; el tiempo lo cambiará; bien lo sé, como el invierno cambia el de los árboles. Mi amor a Heathcliff semeja las eternas rocas que están debajo de un manantial de escaso placer visible, pero necesario. ¡Nelly, yo soy Heathcliff! Él está siempre en mi pensamiento, no como cosa agradable, de igual manera que yo no soy siempre agradable para mi misma, sino como mi propio ser (p. 16i).

Qué duda cabe de que la novela está inscrita dentro de la más pura tradición romántica. En tanto que Catherine se casa con Linton ha de pagar las consecuencias: Heathcliff huye, se hace rico y vuelve años después para ejercer su venganza contra aquellos que los sobajaron sea en "Wuthering Heights" o en "Thrushcross Grange". Su vindicación ha de ser implacable. Se casa con Isabelle Linton y es su desgracia de por vida. Arruina a Hindley y sumerge a Catherine en un torbellino de pasión en un intento de recuperar su amor. Debe notarse que Heathcliff usa su nuevo status, así como su reciente poder económico, para perpetrar su venganza contra aquellos que lo humillaron mientras fue pobre. Pero, al contrario de Jay Gatsby, por ejemplo, Heathcliff no intenta recobrar el amor haciendo alarde de su riqueza. Él no establece la ecuación amor igual a riqueza.

De hecho, Heathcliff se halla muy cerca del ideal del héroe byroniano: es un hombre orgulloso, agresivo, de mirada desafiante y de oscuro pasado. Es extremadamente vengativo y, sin embargo, capaz de sentir los más fuertes y profundos afectos. No es casual que cuando Mr. Earnshaw lo lleva a su casa, al inicio de la novela, describa su físico diciendo que era "moreno casi como si hubiera salido del infierno". Y en efecto, a la postre resulta que Heathcliff es un personaje diabólico cuya moral bien pudo haber emanado de la pluma de Byron o de Blake. Lo curioso es que en la creación de su protagonista Brontë no haya hecho concesión alguna. Al contrario de lo que sucede con la mayor parte de las novelas de la época, la autora frustra toda expectativa encauzada a descubrir un resquicio de bondad tras el atormentado corazón de Heathcliff. Él no siente compasión por nadie. $\mathrm{Ni}$ siquiera por la joven Cathy ni por Hareton que son totalmente ajenos a su tragedia.

Heathcliff no se comporta de acuerdo con las normas morales prevalecientes en su sociedad. El crea su propio código, que consiste en subordinar todos los principios morales y sociales a la inmensa e incontenible pasión que siente por Catherine. No incurre en el adulterio pero desafía las convenciones más caras de la época en el pasaje en el que irrumpe en la alcoba de Catherine, besándola y abrazándola, poniendo en entredicho la autori- 
dad social y moral de Linton, esposo legal de Catherine. Nelly Dean queda horrorizada ante el atrevimiento de Heathcliff y siente pánico cuando escucha que Linton se aproxima. Heathcliff piensa en huir, pero Catherine lo disuade, convirtiéndose así en su más flagrante cómplice. Comparten una misma moral: la de la pasión y a través de ella, como ya antes lo había augurado, Catherine se convierte en Heathcliff, es Heathcliff.

De manera similar, luego de la muerte de Catherine, Heathcliff, desgarrado, clama que no puede vivir "sin su vida, sin su alma". La concepción romántica de que el amor es capaz de trascender hasta la propia muerte se postula en esta novela como la única alternativa viable para que la autora logre unir finalmente a sus enardecidos amantes. Emily Brontë inicia su novela con la intención de hacerle saber al portavoz de su primera narrativa, el "dandy" Lockwood, la historia de la gran pasión de Heathcliff -su "landlord"- y culmina instruyéndonos, a nosotros lectores, y acaso a ella misma, sobre la intensidad y el riesgo que implica vivir una pasión capaz de regir nuestra conducta.

Middlemarch, la tercera y última novela bajo estudio, tiende hacia una síntesis en relación a sus dos predecesoras. No es casual que el pueblo en donde ocurre la historia lleve el nombre de 'Middlemarch' (media-marcha). Dorothea Brooke, la protagonista, no difiere en gran medida, en cuanto a sus intereses, de los de Elizabeth o de Catherine Earnshaw ya que también busca el matrimonio como fin último. Hay que admitir, empero, que Middlemarch, como novela, tiene un espectro mucho más rico que el de sus prececesoras tanto en su complejidad temática como en sus alcances. Es por ello que esta novela tiene más puntos en común con Pride and Prejudice que con Wuthering Heights, ya que la novelista concentra su interés en un amplio rango social y explora la actitud no de una, sino de varias mujeres, así como de sus respectivas parejas, en relación a la institución del matrimonio (amén de sus indagaciones sobre el trabajo, la política, el dinero que corren paralelas en la obra) entre lo que se llamaba the country gentry inglesa. Hay que aceptar también que Eliot contempla los sucesos con una mente más profunda y filosófica que la de Austen y que la de Brontë, como se intentará demostrar en su oportunidad.

Con todo, existen semejanzas entre las protagonistas que vale la pena señalar. Dorothea juega un papel similar al de Elizabeth en tanto que es el carácter más complejo entre las mujeres casaderas de Middlemarch. Su relación con respecto a Celia, a Rosamund y a Mary Garth es muy parecida a la que lleva Elizabeth Bennet con sus hermanas y la función que dicha relación tiene en el desarrollo orgánico de la novela es prácticamente la misma: mostrar diversas actitudes de los protagonistas en torno a la la elección matrimonial. Dorothea está caracterizada como una mujer de decisiones, que sabe lo que quiere, inteligente y graciosa aunque suele caer también, en ocasiones, en el auto-engaño y la ingenuidad. Su hermana Celia 
y su prometido James Cheetam, por otra parte, son tan simplones como Bingley y Jane Bennet en Pride and Prejudice. Celia excede incluso a Jane ya que ni siquiera se percata de que en principio Cheetam estaba interesado en casarse con Dorothea y no con ella. Celia es un personaje que no puede siquiera imaginar - no se diga comprender- las inquietudes sentimentales y morales que aquejan a Dorothea, su hermana mayor. A través de toda la novela repite, acaso con razón pero no por los argumentos que ella esgrime, que Dorothea actúa siempre de forma equivocada. Pero, como en el caso de Jane Bennet, la autora la justifica en último análisis en razón de sus buenos sentimientos. De modo similar Cheetam, que se convierte en su esposo, acepta la vida al igual que Bingley: sin mayores complicaciones. Su amor por Dorothea resulta tan endeble que a ésta no le cuesta gran esfuerzo convencerlo de que se case con su hermana Jane en lugar de con ella. Cuestión de compatibilidad de caracteres, argüiría algún leguleyo.

Rosamund y Lydgate - como Casaubon y Dorothea a otro nivel- fracasan en su matrimonio de manera mucho más convincente y realista que la mostrada por Austen en su caracterización de Lydia y Wickham. Rosamund, tal y como su nombre lo sugiere, es una bella rosa mundana en cuya mente y corazón privan la superficialidad, la vanidad y el egoísmo. Ella se casa con Lydgate porque cree que podrá usufructuar sus riquezas familiares y porque la atrae el hecho de que él no es originario de Middlemarch. Pasa por alto que Lydgate es un modesto doctor que trata de labrar su futuro y al que sus ricos familiares apenas reconocen. El único interés de Rosamund es ella misma y los avatares y problemas de su esposo la tienen sin mayor cuidado. Al percatarse de que no es feliz, Rosamund no acepta el hecho con la pasiva resignación de Dorothea sino que busca seducir a Will Ladislaw con resultados atroces para ella. El fracaso y la desintegración moral y física del doctor Lydgate, su esposo, se inician a partir del momento en que decide casarse con Rosamund, pero se agravan en tanto que es incapaz de vivir de acuerdo con sus recursos y dentro de los límites que le imponen su status social y su poder económico. En su intento de responder a las exigencias y veleidades de Rosamund empieza por perder su ética profesional, su solvencia económica y el amor de su mujer y termina perdiendo el control sobre sí mismo para fenecer irremediablemente.

La relación entre Fred Vincy y Mary Garth ofrece una variante dentro de las perspectivas matrimoniales expuestas por las predecesoras de Eliot. Ellos representan la imagen de lo que Eliot consideraba un "matrimonio de sólida y mutua felicidad". Su eventual unión se logra más a causa de los esfuerzos y privaciones de la familia Garth, así como de la generosa y desprendida ayuda del pastor Farebrother, que a causa de los propios méritos de Fred Vincy, cuyo carácter se granjea las simpatías del lector tal vez a causa de su ingenuidad sin límite y de su poca visión para los aspectos prácticos de la vida. La novelista parece realzar que, a pesar de todos sus 
defectos, Fred, al igual que Mary, poseían tan clara determinación de amarse: uno a otro que eso es lo que les permite sobrellevar con decisión y fortaleza las muchas vicisitudes que les ocurren en el curso de la novela. Parece: como si Eliot hubiese querido demostrar que gente honesta, sencilla y trabajadora como los Garth es más susceptible de ser feliz en la sociedad de Middlemarch que los que están por encima de ellos como los Vincy o los. Bulstrode. Por lo mismo es interesante notar que Vincy desciende en la escala social -en lugar de que su esposa ascienda como sucede con Elizabeth en Pride and Prejudice- y gracias a ello logra superar sus errores y valorar el amor de Mary y su familia.

La ética de George Eliot se trasluce a través de los ejemplos citados: para ella los personajes que sobreviven son ejemplares y estimulantes mientras aquellos que se desintegran merecen su condena y su reproche. Eliot reprueba las vacilaciones de la voluntad, del carácter, de la justicia y del trabajo.

Pero concentrándose en la heroína de la novela podrá notarse que Dorothea Brooke acusa diferencias de importancia con respecto a las otras dos protagonistas ya tratadas. En Pride and Prejudice Elizabeth Bennet se pasa la mayor parte de la novela desarrollando su táctica para conquistar a Darcy y la obra culmina en el momento en que logra casarse con él. Catherine Earnshaw, por otra parte, como Dorothea, comete un error al elegir marido. Pero mientras la heroína de Brontë se equivoca por seguir las normas del orden social por encima de sus sentimientos, Ia de Eliot se equivoca por anteponer las razones de orden intelectual a las emotivas. Ambas se dejan llevar por las apariencias pero es importante notar que sus búsquedas se dan en sentidos muy distintos, pues Dorothea Brooke jamás toma comocriterio de elección la apariencia física o el status económico o social de su futuro esposo. Casaubon, su primer marido, que a sus ojos luce como. un hombre sabio intelectual, resulta, cuando lo conoce a fondo, un viejogárrulo escribano de temas misticoides, inconexos y baladíes. Una vez casada con Casaubon, Dorothea asume y sobrelleva su error y su destino con paciente y puritana resignación. Tal parece como si en la concepción moral de la novela, George Eliot no hubiera encontrado otro recurso para deshacerse de Casaubon y apartarlo de la vida de Dorothea que el de matarlo. Una vez que Casaubon desaparece "por muerte natural", Eliot coloca a la joven viuda Dorothea en la actitud original de Elizabeth Bennet: lista para dedicarse de nuevo a buscar marido. Desde el inicio de Middlemarch el lector se percata de que Dorothea siente una fuerte predisposición en favor de su sobrino político Will Ladislaw. Y aunque éste ejerce una atracción mucho mayor que la de su marido, la novelista los mantiene aparte hasta el deceso de Casaubon. Es importante notar cómo resuelve Eliot los conflictos de su novela en comparación con las otras dos autoras. En tanto que Dorothea es rica y no tiene necesidad de ascender en la escala social 
la novelista hace que su heroína renuncie a su "posición y fortuna" para que logre casarse con Ladislaw que no es ni bien nacido, ni tiene propiedades. Eliot ha asumido exactamente la posición opuesta a la de Austen, acercándose a la de Brontë, en tanto que ha inclinado finalmente a su heroína en favor de la integridad emocional y en contra de la seguridad social y del status económico. Dorothea, como Catherine, aprende de su error, y su decisión final la ejerce siempre con su pasado en mente. La diferencia de actitud estriba en que mientras Brontë subvierte el orden imperante, Eliot simplemente lo altera. Los comentarios finales de Middlemarch muestran qué tan consciente era Eliot de su posición moral y del significado que tiene la actitud que le atribuye a su protagonista.

Ciertamente aquellos actos determinantes de su vida no eran de una belleza ideal. Eran una mezcla de un impulso joven y noble debatiéndose con las condiciones de un estado social imperfecto en el cual los grandes sentimientos toman a menudo el aspecto de errores y la fe el aspecto de [que les daba] lo ilusorio... la impresión que les daba a quienes la rodeaban era difusa: pues la mejora del mundo se debe en parte a actos ahistóricos; y que las cosas no estén tan mal para nosotros como podrían estar se debe en gran medida a aquellos que vivieron fielmente una vida oculta y que descansan en tumbas poco frecuentadas (p. 896).

Por su parte, Will Ladislaw está caracterizado como un personaje con rasgos más románticos que Darcy pero menos que Heathcliff, menos convencional que el primero pero mucho más que el segundo. La gran atracción que ejerce Darcy en las chicas núbiles de Longbourn y Netherfield se basa principalmente en su riqueza - que está en relación directa con su orgullo y su arrogancia- y en su apostura física. Heathcliff, como se señaló, es un auténtico paria: violento, pasional y desafiante, con un único objetivo en mente: Catherine. El Will Ladislaw de Eliot resulta una combinación entre los dos héroes antes aludidos. Will Ladislaw comparte con Darcy su orgullo y con Heathcliff su pobreza, su oscuridad (física y de origen) y su sangre de paria que en Middlemarch está descrita como una "pavorosa mezcla":

Era una especie de gitano, que disfrutaba la sensación de no pertenecer a ninguna clase; su actitud correspondía a la de un personaje de romance y disfrutaba de provocar pequeñas sorpresas dondequiera que iba. (p. 502).

Sin embargo, como personaje, Ladislaw es difuso. Empieza como pintor, luego se torna poeta y termina como político; es una especie de rebelde asimilado finalmente al sistema social imperante. Ladislaw también ostenta, aunque con cierta timidez, algunas características del héroe romántico, pero se convierte al final en una alegoría de la voluntad (Will, en la intrincada 
búsqueda moral que Dorothea Brooke se impone a lo largo de las casi mil páginas de la novela. Comparados con Heathcliff tanto el orgullo y la rebeldía de Darcy como los de Ladislaw alcanzan a ser apenas actitudes menos que timoratas.

Podrá observarse que, como lo ha señalado Shorer, ${ }^{6}$ el lenguaje de Eliot se basa en metáforas de unificación, de antítesis (represión-libertad), de progreso, de apocalipsis. En sus novelas abundan palabras como "altura", "luz", "revelación", usadas con el fin de que la novelista pueda expresar una visión optimista del mundo en la que el individuo contribuye decisiva aunque modestamente para el mejor desarrollo de la humanidad.

En suma, los protagonistas de Austen aceptan a su sociedad -así como sus. convenciones morales y económicas - tal y como es: en su integridad. Todo lo que sus personajes deben hacer en el curso de la novela es ajustar sus hábitos y costumbres a las exigencias del mundo en el que viven. En contraste, los héroes de Emily Brontë rechazan de manera tajante las convenciones. morales y sociales de su tiempo y asumen una actitud más romántica y más radical. Esto hace que muchos críticos se sientan un tanto incómodos, pues. el carácter de la novela es definitivamente subversivo y está totalmente teñido de ese sentido de "posibilidad" propia de las obras de arte que buscan cambiar el estado imperante de las cosas. Los personajes de Eliot se hallan entre estos dos fuegos. Ellos rechazan las convenciones sociales de las. que descreen y sólo aceptan una parte mínima para sobrevivir. En efecto, al final de Middlemarch Dorothea y Ladislaw no se "integran" sino solamente se "adaptan" a las exigencias de su medio ambiente. Es a través de "vivir fielmente una vida oculta" y de sobrellevar congruentemente los nimios eventos "ahistóricos" en donde Eliot encuentra la justificación de sus. personajes y a través de ellos, la suya propia.

\section{BIBLIOGRAFIA}

Austen, Jane, Pride and Prejuice, Great Britain, Penguin Books, 1972.

Brontë, Emily, Wuthering Heights, Great Britain, Colins, 1948. (Cumbres borrascosas. Trad. de María Rosa Lida. Sudamericana.)

Eliot, George, Middlemarch, Great Britain, Penguin Books, 1971.

Kettle, Arnold (ed.), The Nineteenth Century Novel, Great Britain, Heinemann Educational Books, 1977.

Lukács, Georg, Marxism and Human Liberation, Ed. by E. San Juan Jr. New York, Delta, 1973.

Levin, Harry, The Gates of Horn: A Study of Five French Realists, New York, Oxford University Press, 1966.

Maugham, W. Somerset, Ten Novels and their Authors, Great Britain, Penguin Books, 1969.

Prichet, V. S., The Living Novel, London, Chatto and Windus, 1966.

6 Schorer, op. cit., p. 41. 
Rubinstein, E. (ed.), Twentieth Century Interpretations of "Pride and Prejudice", New Jersey, Spectrum Books, 1969.

Shorer, Mark, The World we Image, New York, Farrar, Strauss and Giroux, 1968.

Van Ghent, Dorothy, The English Novel: Form and Function, New York, Harper and Row, 1961. 